\title{
Diagnosis and Management of Melanoma of the Scalp: A Review of the Literature
}

\author{
Gaetano Licata' \\ Camila Scharf' \\ Andrea Ronchi ${ }^{2}$ \\ Sebastiano Pellerone (D) ${ }^{1}$ \\ Giuseppe Argenziano' \\ Pasquale Verolino $\mathbb{1}^{3}$ \\ Elvira Moscarella' \\ 'Dermatology Unit, Department of \\ Mental and Physical Health and \\ Preventive Medicine, University of \\ Campania Luigi Vanvitelli Naples, Naples, \\ Italy; ${ }^{2}$ Pathology Unit, Department of \\ Mental and Physical Health and \\ Preventive Medicine, University of \\ Campania Luigi Vanvitelli Naples, Naples, \\ Italy; ${ }^{3}$ Plastic Surgery Unit, \\ Multidisciplinary Department of Medical- \\ Surgical and Dental Specialties, University \\ of Campania Luigi Vanvitelli Naples, \\ Naples, Italy
}

Correspondence: Giuseppe Argenziano Email g.argenziano@gmail.com

\begin{abstract}
Cutaneous melanoma is a public health issue and the head and neck region is of particular interest, despite accounting for only $9.0 \%$ of the total body surface, it harbours $20 \%$ of melanoma cases. Data from the literature show that scalp melanomas (SM) carry high mortality rates, with a 10 -year survival rate of $60 \%$ which lead them to be named as the "invisible killer". Moreover, SMs are more common in the elderly than in young population, and they occur six times more frequently in men than in women. This is probably related to the higher incidence of androgenetic alopecia and a higher cumulative and intermittent ultraviolet damage on the scalp. Histologically, SM is a heterogenous group, including lentiginous melanoma (LM), desmoplastic melanoma, superficial spreading and nodular melanoma. Thin melanomas tend to display an atypical network or pseudo-network and regression in dermoscopy. Blue-white veil, irregular pigmented blotches and an unspecific pattern are most commonly detected in thick lesions. On reflectance confocal microscopy (RCM), the most frequent pattern is irregular meshwork, but also ringed and disarranged pattern have been described. Differential diagnosis includes benign solar lentigo, actinic keratoses, lichen planus like keratosis, melanocytic nevi and blue nevi. All suspicious lesions should be biopsied; therefore, an excisional biopsy with $2 \mathrm{~mm}$ margins is usually the best option. The management of SM is the same as for melanoma on other body sites. However, sentinel node biopsy tends to be more challenging, as well as achieving adequate excision margins of the primary tumor. In this review, we summarize clinical, pathologic, dermoscopic and RCM features of SM, and focus on its epidemiology, risk factors and best management options.
\end{abstract}

Keywords: scalp, melanoma, dermoscopy, reflectance confocal microscopy

\section{Introduction}

Cutaneous melanoma is a public health issue, particularly in fair-skinned populations. It is a complex neoplasm thought to arise from multiple genetic and environmental factors. ${ }^{1}$ The head and neck region is of particular interest, despite accounting for only $9.0 \%$ of the total body surface, it harbours $20 \%$ of melanoma cases. $^{2}$ Melanomas of the head/neck occur mostly in elderly patients, and the current increase in life expectancy of the population should resolve in a higher incidence of this subtype of melanoma. ${ }^{3}$

Scalp melanoma (SM) represents $35 \%$ of cases of head and neck melanomas and is accountable for $5 \%$ of all melanomas. ${ }^{4}$ Data from the literature show that SMs carry the highest mortality rates, with a 10 -year survival rate of $60 \%$ which lead them to be named as the "invisible killer". Additionally, SM is characterized by a risk of death nearly 2 times higher than the ones located on the extremities. ${ }^{5}$ 
Ozao-Choy et $\mathrm{al}^{6}$ proved that scalp location is an independent risk factor for worse overall survival and specific melanomas survival. Staging of scalp melanoma is performed according to TNM staging system. ${ }^{7}$ The poor clinical outcome associated with SM has been attributed to several factors including delayed diagnosis due to poor visibility of the area (hair coverage); a higher proportion of melanomas with rapid vertical growth, such as nodular and desmoplastic melanomas; a more aggressive nature related to anatomical features such as abundant lymphatic and blood drainage and finally the difficulty of obtaining adequate surgical margins. ${ }^{8}$ This knowledge indicates that there is a need to improve the early detection of melanoma on this specific location.

The aim of this review is to summarize the clinical, dermoscopic and confocal microscopy features that allow an early diagnosis of scalp melanoma and to analyse the most appropriate management for this peculiar location.

\section{Epidemiology and Risk Factors}

Several population studies have shown that the head and neck melanoma are more frequent in the elderly than in young population. Mean age of patients with SM is 65 years, nearly 10 years older than patients with melanomas located on the trunk or limbs (65 years vs 55 years). ${ }^{9}$ In addition, the mean age of patients who have melanoma placed on the other areas of the head and neck is slightly lower than patients with SM. Differences in terms of incidence between sexes have been described; indeed, SM occurs six times more frequently in men than in women. ${ }^{10}$ This is probably related to the higher incidence of androgenetic alopecia and a higher cumulative and intermittent ultraviolet damage on the scalp. Signs of chronic sun damage and history of previous skin cancer are frequently found in patients developing SM. ${ }^{11}$ Benati et $\mathrm{al}^{12}$ recently found that melanomas on bald scalp were thicker than melanomas on hairy scalp in a sample of 33 cases. In this study, scalp was subdivided into three groups: hairy scalp, scalp with thinning hair and hairless (bald) scalp. Patients with melanoma on hairy scalp were younger, and there was a higher percentage of women than the group with thinning hair or bald scalp. Furthermore, hair covering reduces exposure to UV by up to $81 \%$ and provide protective effect against chronic sun damage, ${ }^{13}$ and median Breslow thickness was $0.5 \mathrm{~mm}$. Conversely, patients with melanoma on thinning hair or hairless (bald) scalp had thicker lesions, with the median Breslow thickness being $1.1 \mathrm{~mm}$ for scalp with thinning hair and $3.4 \mathrm{~mm}$ for hairless scalp and there were prominent signs of sundamage. Therefore, according to Benati et al, ${ }^{12}$ melanoma tends to occur in younger patients on hairy scalp compared to melanoma located on bald scalp that appears to be dependent on UV-damage rather than genetics. In addition, melanomas arising on bald scalp are thicker than those found on hairy scalp as they arise in older patients who are less prone to require a medical consultation, and this could cause a diagnostic delay.

In contrast to the study of Benati et al, Pereira et $\mathrm{al}^{14}$ identified 113 melanomas of the scalp and they found that melanomas of hairy scalp were more frequently invasive $(81 \%)$ and had higher median Breslow thickness (0.8$1.3 \mathrm{~mm}$ ) than those arising on bald scalps. However, they added, when considering only the invasive cases, Breslow thickness was not different among different categories of hair coverage. Considering these results, Pereira et $\mathrm{al}^{14}$ concluded that there are two different scenarios: Lentigo Maligna (LM) and non-LM subtype of SM. Elderly patients with androgenic alopecia and photodamage tend to develop LM type of melanoma, the melanomas are detected before becoming invasive because they appear on visible areas and are of a slow growing subtype. The second scenario includes other subtypes of melanomas that arise on the hairy scalp of younger individuals. These hair-covered melanomas, despite being rare, are usually invasive because due to the location they are diagnosed late.

Therefore, routine examination of the scalp is recommended at least in high-risk population (bald elderly men) to ensure early detection of melanoma and non-melanoma skin cancers. In this regard, the role of hairdressers has been recently investigated, highlighting their usefulness for the detection of SM via population-based screening and dermatologic referral. ${ }^{15}$ Reasonably hairdressers, have a chance of detecting any evolving scalp lesion at an early stage, also in younger patients with hair covering. At the same time, a valid alternative could be to involve the partners for a scalp evaluation, in order to highlight the presence of any suspected lesions. ${ }^{16}$

\section{Pathogenesis}

Several genetic mutations are known to influence and contribute to the development of melanoma. Studies demonstrated that SM is more likely to harbour mutations of CCND1 and CDK4 oncogenes. On the other hand, melanomas of non-chronically exposed skin are expected to manifest mutations of BRAF, NRAS and loss of 
chromosome $10 .{ }^{17,18} \mathrm{~N}$-ras oncogene is a common genetic mutation occurring in $18 \%$ of cutaneous melanomas. This mutation is frequent in nodular melanoma arising in areas of chronic sun-damage. Owing to its location, scalp is particularly susceptible to chronic sun damage and the associated mutations. ${ }^{19}$ Jiveskog et $\mathrm{ll}^{20}$ compared the incidence of N-ras mutations between sun-exposed areas such as scalp, head and neck, to sun-protected areas of the body and discovered N-ras to be mutated in $32 \%$ of head and neck melanoma specimens, but only $7 \%$ of melanomas harbouring this mutation in photo-protected areas. N-ras mutation is associated with thicker lesions and higher rates of mitotic activity, which is also present in melanomas with more aggressive behaviour such as SM.

\section{Histopathology}

SM includes different histological subtypes. Melanomas are classified according to the degree of cutaneous solar damage. SMs related to high cutaneous solar damage include lentiginous melanoma (lentigo maligna melanoma) and desmoplastic melanoma, whereas SMs related to low cutaneous solar damage include superficial spreading melanoma. Nodular melanoma is also relatively frequent in the scalp, regardless of the degree of cutaneous solar damage. ${ }^{21}$

In subjects with bald scalp or with thinning hair, the subtypes related to the high solar damage are the most common. Lentiginous melanoma is characterized by a continuous lentiginous pattern of growth, with the presence of few junctional nests. ${ }^{22}$ Desmoplastic melanoma mainly develops in the dermis and may simulate a scar tissue, being constituted by a poorly to moderately dense population of spindle cells separated by delicate collagen fibers. $^{23}$ Overall, melanoma associated with high solar damage typically have a very high mutation burden, with predominant UV signature mutations, like NF1, BRAF (non-V600E mutations), NRAS, KIT, ERBB2, MAP2K1, MAP3K1, BRAF (non-canonical mutations), EGFR, PTPN11, MET, RAC1, SOS2, NRAS, and PIK3CA mutations. $^{24-27}$

\section{Dermoscopy of SM}

In the past decades, dermoscopy was proved to improve the early detection of melanoma; in 2012 Stanganelli et $\mathrm{al}^{28}$ described the dermoscopic pattern of scalp naevi and melanoma. This group showed that their melanoma series displayed dermoscopic features typical of both lentigo maligna (LM) and superficial spreading type melanoma. Moreover, Zalaudek et $\mathrm{al}^{29}$ described that in contrast to the dermoscopic features seen in melanoma occurring on the face, the same morphologic type of network seen in melanoma of the trunk was observed in SM. In 2017, a recent study by the International Dermoscopy Society also came to the same conclusion that SM may present dermoscopic features of both facial and body melanoma. Roughly, thin melanomas tend to display an atypical network or pseudo-network and regression in dermoscopy, being dermoscopically similar to LM. Blue-white veil, irregular pigmented blotches and an unspecific pattern are most detected in thick lesions. ${ }^{30}$

This high dermoscopic variability is due to the possibility to find on the scalp area a variety of melanoma subtypes: lentigo maligna (LM) and lentigo maligna melanoma (LMM); superficial spreading melanoma de novo or nevus associated, and nodular melanoma. Moreover, a rare melanoma subtype, the desmoplastic melanoma is more often found on the head/neck area.

LM and LMM show an atypical pseudo network in dermoscopy with increasing hyperpigmentation and obscuration of follicular openings with increasing Breslow thickness. ${ }^{31}$ Differential diagnosis includes benign solar lentigo, actinic keratoses, lichen planus like keratosis. (Figure 1) Therefore, as for flat pigmented lesions of the face, also for scalp lesions it is possible to evaluate the presence of criteria for benignity in dermoscopy, such as scales, white follicles, erythema/reticular vessels, reticular and/or curved lines/fingerprints, sharp demarcation, and classic criteria of seborrheic keratosis. In the absence of benignity criteria surgical excision is warranted. $^{32}$ Superficial spreading melanoma may display all the well-known dermoscopic melanoma features summarized in the 7-point check list, namely atypical network, blue-white veil, atypical vascular pattern, irregular streaks, irregular pigmentation, irregular dots and globules, regression structures ${ }^{33}$ (Figures 2 and 3).

Nevus-associated melanoma (NAM) represents $30 \%$ of melanomas overall ${ }^{34}$. In dermoscopy NAMs tend to show atypical pigment network and regression structures more often, when compared to de novo melanomas (DNM). A previous study by Shitara et $\mathrm{al}^{35}$ observed that the presence of globules, streaks and negative pigment network were significantly related to a NAM the latter being the most specific criterion, in contrast, the presence of blue-white veil was related to absence of associated naevus in this study (Figures 4 and 5).

Differential diagnosis of SSM of the scalp includes scalp nevi. When discussing specifically lesions of the 

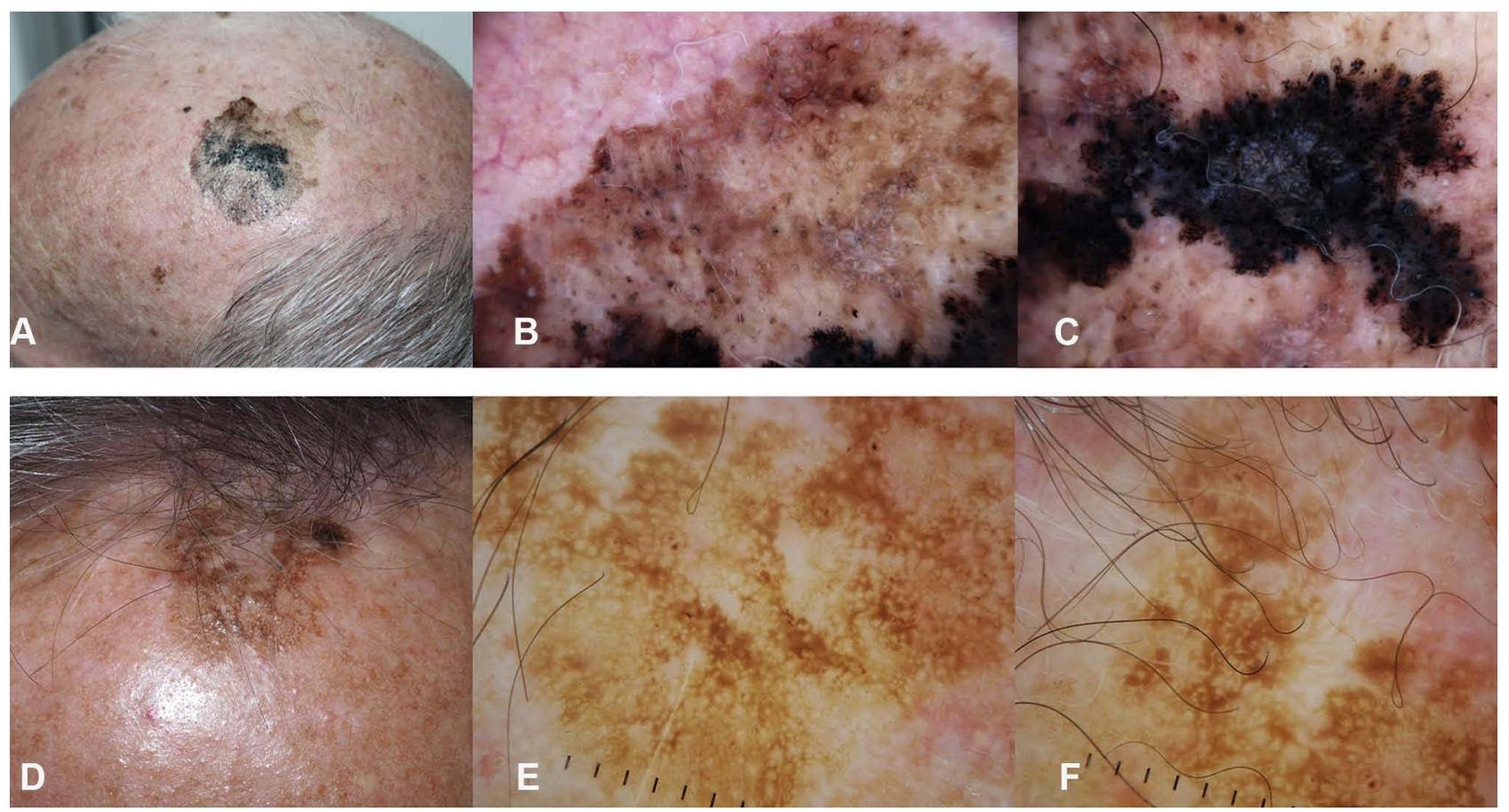

Figure I Lentigo maligna melanoma on the scalp of a 78-year old man with androgenic alopecia (A-C) and solar lentigo on the scalp of a 8 I-year old man. (D-F) (A) Clinical appearance of the LMM. A large macule, variegated in color from light to dark brown to black with ill defined borders. In the background, signs of extensive sundamage. (B) Dermoscopy showing a brown pseudo network with grayish circles around follicular openings and white streaks. (C) Dermoscopy of the hyper pigmented part, with obliteration of follicular openings, blue white veil and irregular dots. (D) Clinical appearance of a solar lentigo: a brown macule with a hyperkeratotic component. (E and F) Dermoscopy showing a light brown pseudo network with evident follicular openings and cerebriform pattern.

head and neck, during childhood nevi tend to be flat and show benign features such as cobblestone pattern, homogeneous pattern and typical pigment network. Targetoid or "crown" appearance have also been described. Afterwards, with aging, these lesions are likely to become dermic and less pigmented. $^{36}$ (Figures 6 and 7) Blue nevi show a preference for scalp location, in dermoscopy they are characterized by structureless blue pigmentation (Figure 8).

Nodular melanoma (NM) can be pigmented or amelanotic, thick invasive nodular melanomas of the scalp frequently show an unspecific pattern (Figure 9). Recently, the blue-black rule ${ }^{37}$ was introduced to increase the diagnostic accuracy with dermoscopy, which can be particularly useful to diagnose pigmented NM. In detail, the BB rule includes the analysis of a combination of blue and black pigmented areas involving at least $10 \%$ of the lesion surface as a feature when identifying NM. The combination of blue and black colour has its substrate in the presence of the pigment not only in the dermis (blue colour), as seen in blue naevi and haemangiomas, but also in atypical melanocytes within the epidermis (black colour). When evaluating the black component comedo- like openings (commonly seen in seborrhoeic keratoses) or lacunae (seen in haemangiomas) should be distinguished. The rule finds its utility mostly when dealing with thick lesions that prevalently make differential diagnosis of SM, such as basal cell carcinoma (BCC), squamous cell carcinoma (SCC), angiomas, blue nevi and seborrheic keratoses. However, BCCs and SCCs tend to have additional dermoscopic characteristics that lead to the diagnosis, such as vascular pattern and absence of pigment network, streaks, regression structures, irregular brown globules, and brown structureless areas ${ }^{37}$ (Figure 10).

In non-pigmented NM, the evaluation of the vascular pattern is crucial, as a milky-red background and irregular vessels are the most common features associated with malignancy $^{38}$ (Figure 11).

Desmoplastic melanoma is challenging, presenting dermoscopically more often as a non-pigmented nodule or papule, with atypical vascular pattern, grey dots, and peppering. When associated with LM, features of LM may coexist (atypical pseudonetwork, blue-grey areas and peppering). This form of melanoma may be difficult to differentiate from dermatofibroma, clinically and on dermoscopy $^{39}$ (Figure 12). 


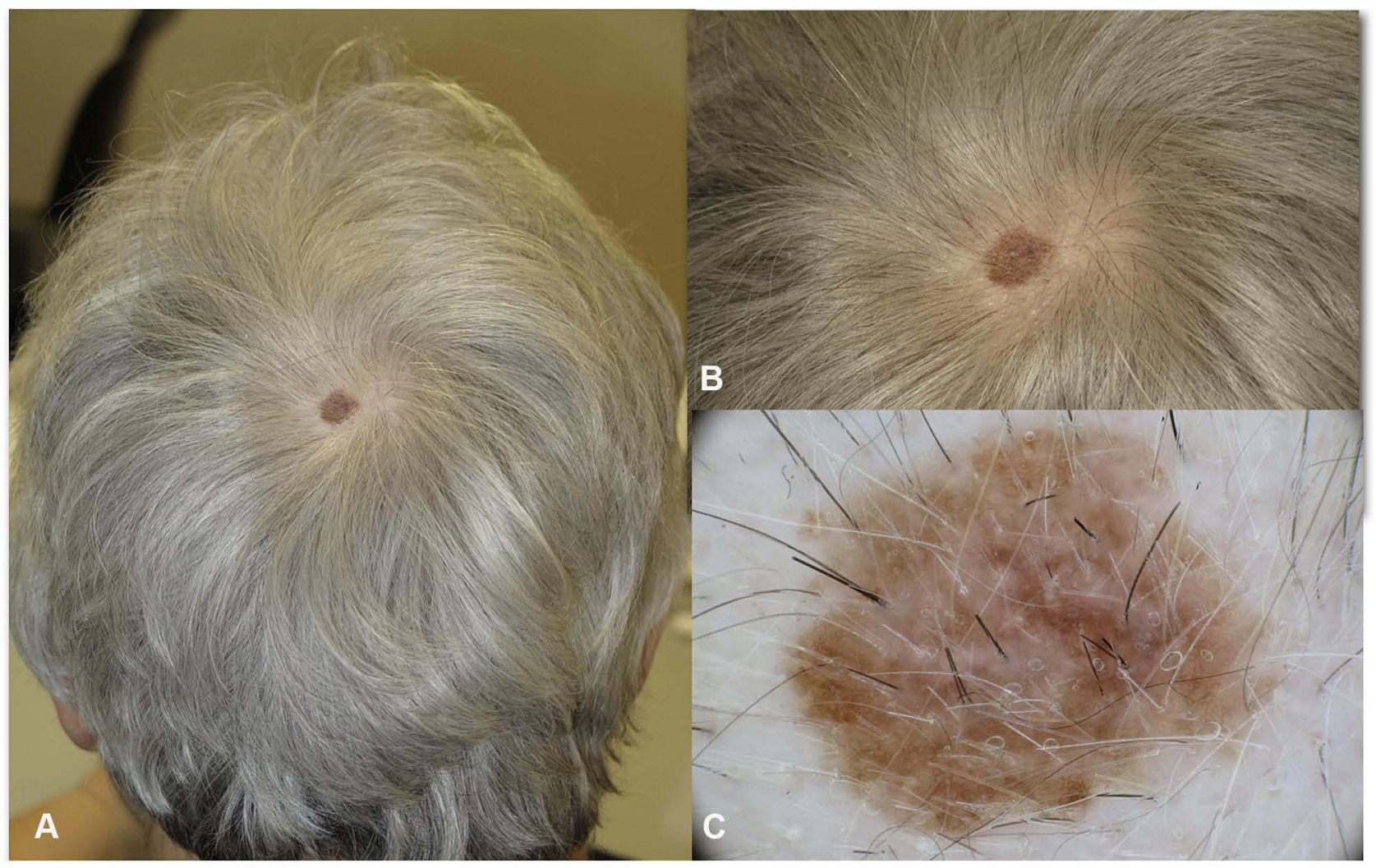

Figure 2 In situ melanoma of the vertex in a 68 year-old woman. (A) The lesion was arising in hair bearing scalp, the patient was not aware of the macule which was noticed by the hair dresser. (B) Close up clinical image, a flat brown macule I cm in diameter. (C and D) In dermoscopy atypical network and regression are detected. No nonprevalent benign pattern.

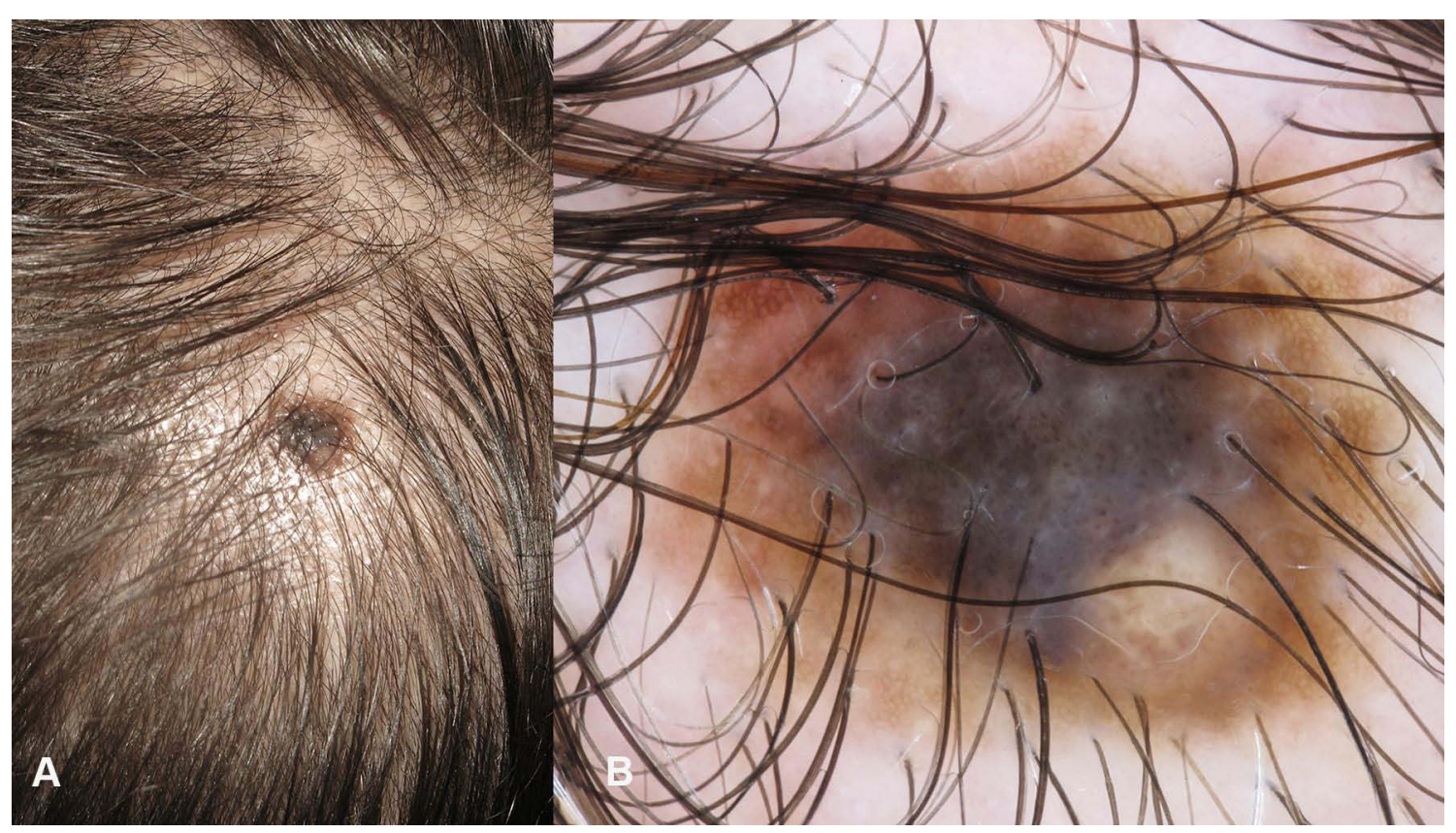

Figure 3 Superficial spreading melanoma on the scalp of a 70 year old man. (A) The lesion is arising in an area of thinning hair due to androgenic alopecia. (B) In dermoscopy, atypical network, irregular globules and blue-white veil are visible. 

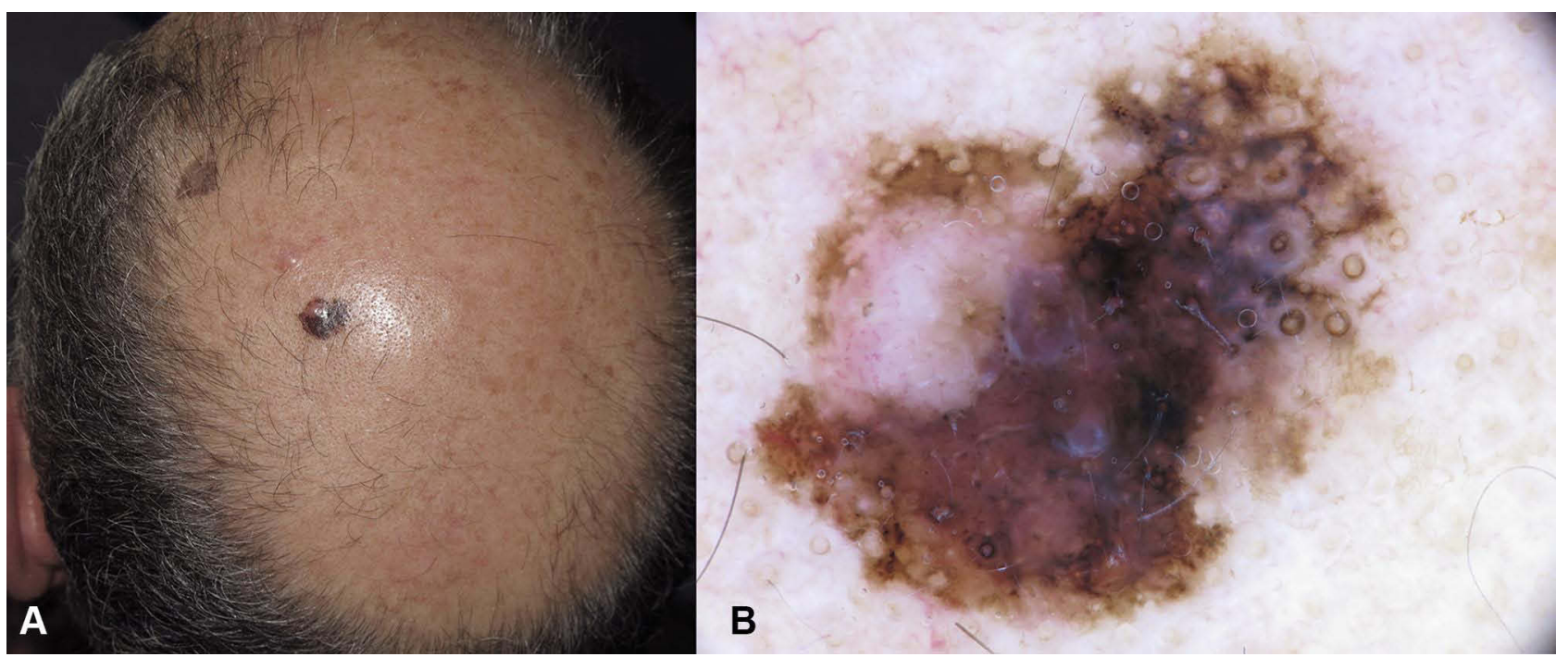

Figure 4 Nevus associated melanoma arising on the scalp in a 60-year old man with androgenic alopecia. (A) Clinically, a asymmetrically pigmented macule is visible surrounding a skin colored papule. (B) In dermoscopy, two components are visible, one flat with atypical pseudo network and obliteration of hair follicles, grey circles, black and brown dots. The pinkish area represents remnants of a dermal nevus.

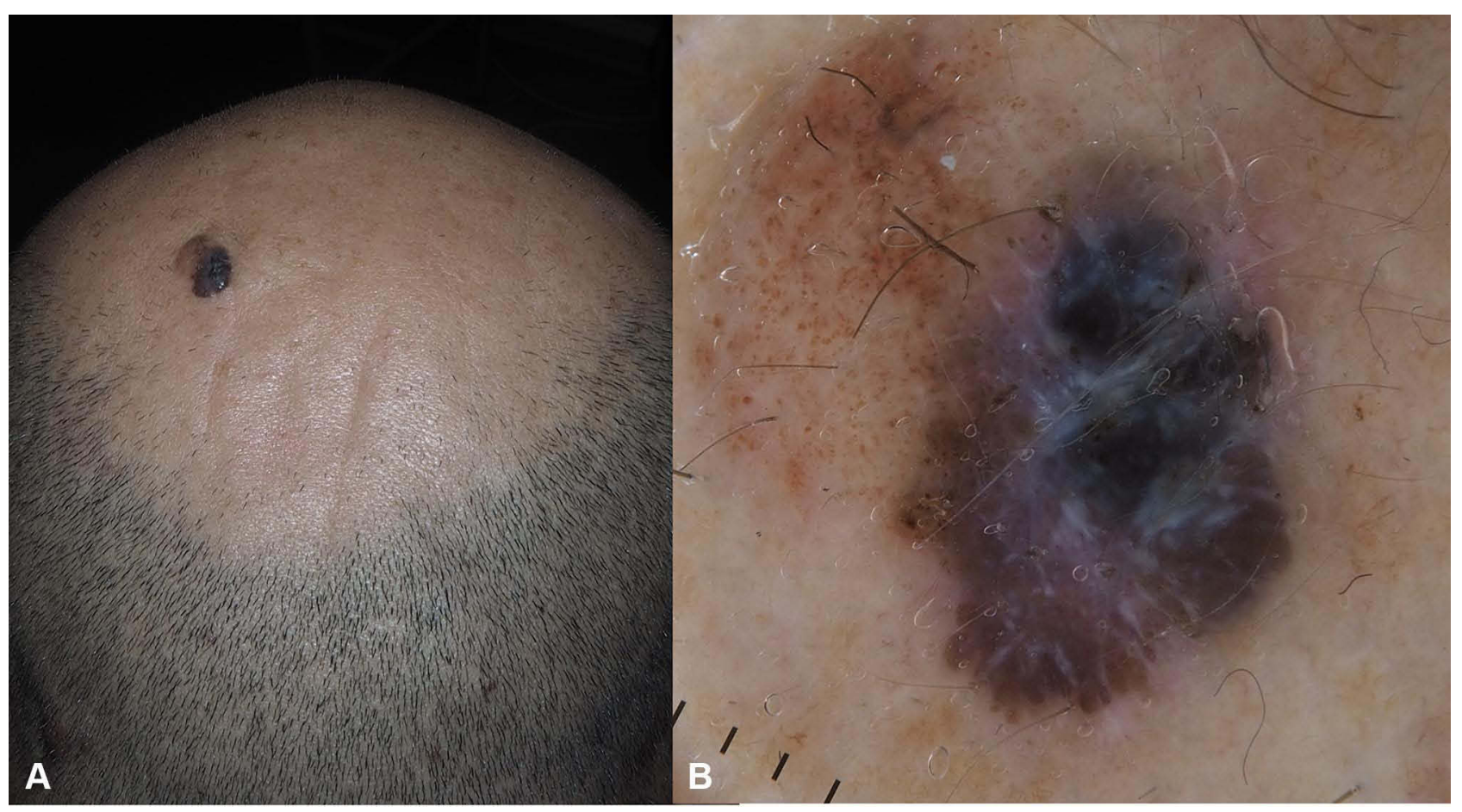

Figure 5 Nevus associated melanoma on the scalp of a 45-year old man. (A) An asymmetric lesion with brown and blue component. (B) In dermoscopy, on one side the congenital nevus with globular pattern is seen, on the other side the melanoma component with blue-white veil, shiny-white streaks.

\section{Reflectance Confocal Microscopy (RCM) Features of SM}

$\mathrm{RCM}$ is a non-invasive diagnostic tool that images skin lesions at an almost histopathological level of magnification. Its utility in skin cancer is undeniable, due to the high reflective index of melanin and keratin, making the correlation between dermoscopy and cytological patterns usually possible. Even though RCM has proved to be very effective in the diagnosis of basal cell carcinomas and melanomas, only a few studies have focused on the features of scalp melanoma. ${ }^{30,40}$ 


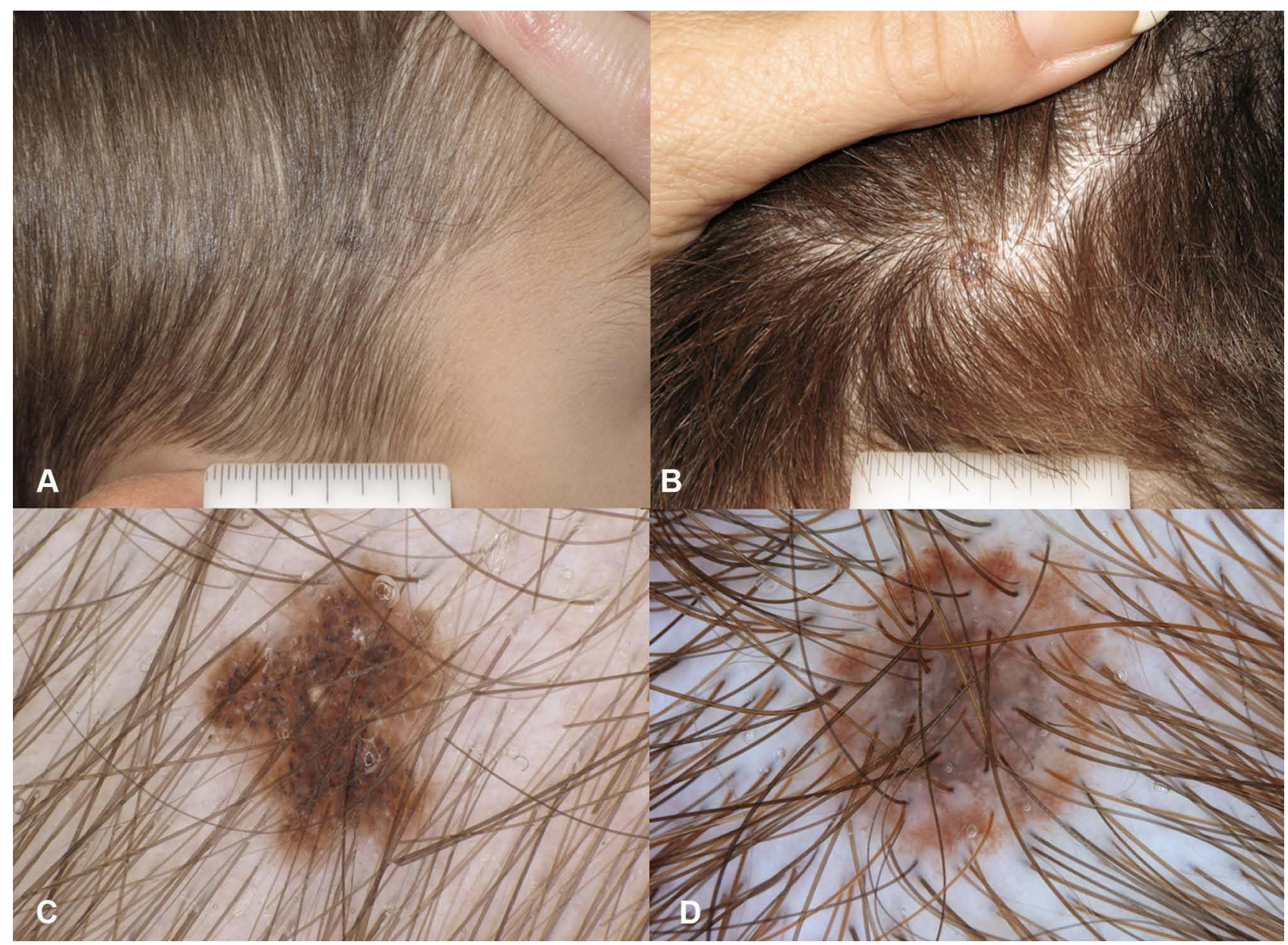

Figure 6 Scalp nevi in children. (A and B) brown pigmented macule on hair bearing scalp. (C) Regular globular pattern. (D) Targetoid pattern in a compound nevus.

Benati et $\mathrm{al}^{30}$ found the most frequent pattern to be irregular meshwork, while other features observed were ringed and non-specific patterns. However, the majority of lesions showed a pagetoid spread, with both round and/or dendritic cells, which is a well-known melanoma feature. Large part of the melanomas had a lentigo-like appearance, the authors also reported bright plump cells that histologically correspond to melanophages, in more than two-thirds of the lesions. In this study, the authors were able to correlate the meshwork and ringed pattern to superficial spreading or in situ melanomas, while the ones that had unspecific patterns on RCM were proven to have extensive regression on histology.

\section{Management}

All suspicious lesions should be subjected to an initial biopsy with a method that provides a definitive diagnosis and the evaluation of the depth of invasion. Therefore, an excisional biopsy with $2 \mathrm{~mm}$ margins is usually the best option. However, when lesions are extensive or excisional biopsy is not possible, incisional or punch biopsies or shave biopsies are reasonable alternative for establishing the diagnosis. ${ }^{41}$ The diagnosis of scalp melanoma is usually possible on clinical and dermoscopy examination; however, a definitive diagnosis is confirmed on histopathological examination only. Dermoscopy and RCM can be very useful tools in making a clinically accurate diagnosis and eventually guide the selection of the best area to biopsy in case of large and extensive lesions. ${ }^{42,43}$ The histology should provide evidence of migration of atypical melanocytes into dermis, Breslow thickness of the tumour, presence of any ulceration, mitotic rate $/ \mathrm{mm},{ }^{2}$ status of the peripheral margins and the deep surface of the lesion. It is critical, thus, to have in hand the analysis of Breslow thickness and ulceration to guide management decisions. ${ }^{44,45}$

Management follows the same principles as for nonhead and neck melanoma. ${ }^{46}$ Breslow thickness of the SM 


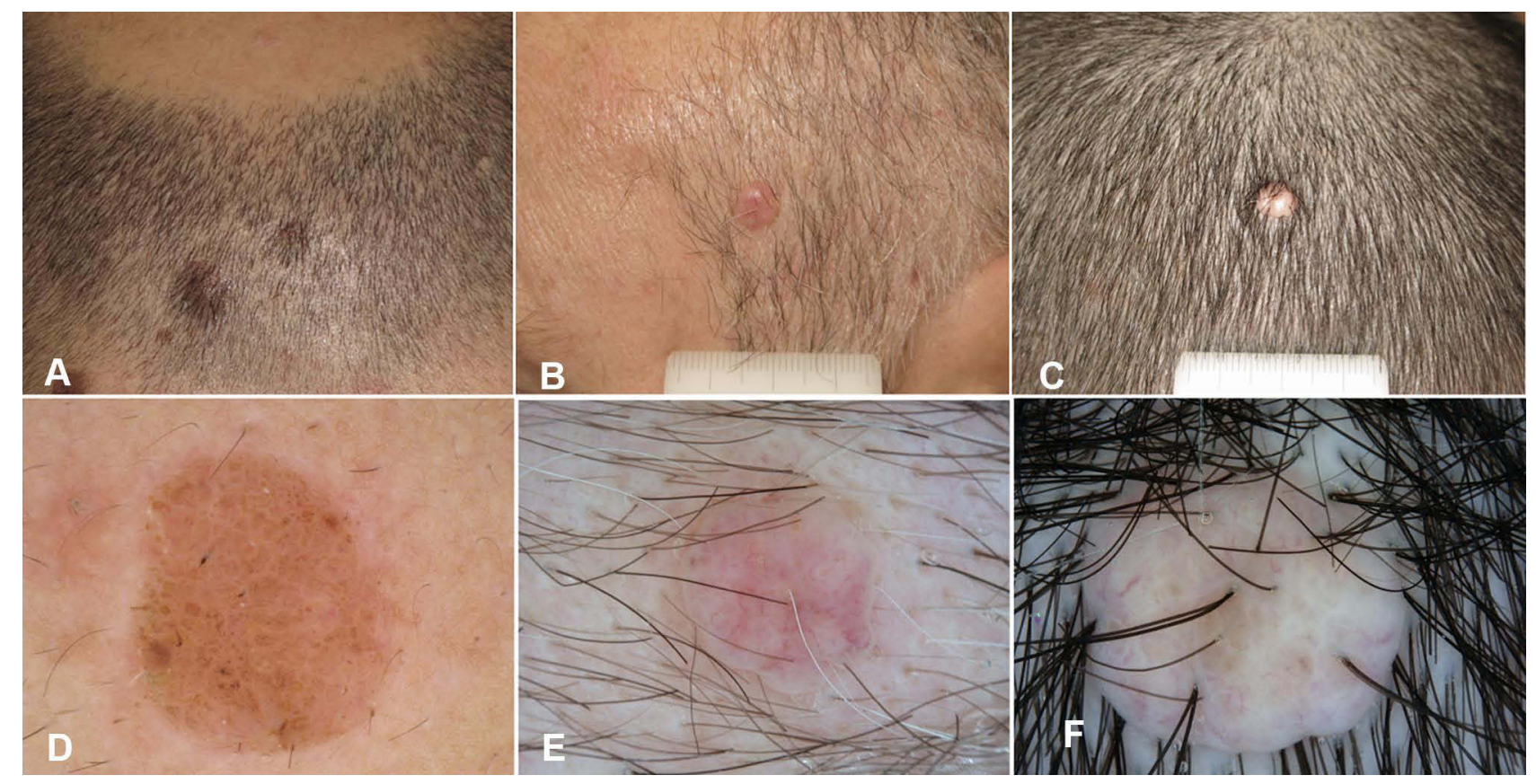

Figure 7 Scalp nevi in adults. (A-C) Clinical appearance of partially pigmented (A) and amelanotic (B and C) dome shaped papules. (D) In Dermoscopy, globular pattern in a compound nevus. (E and F) Dermoscopy of amelanotic lesions: blurred vascular pattern in two dermal nevi.

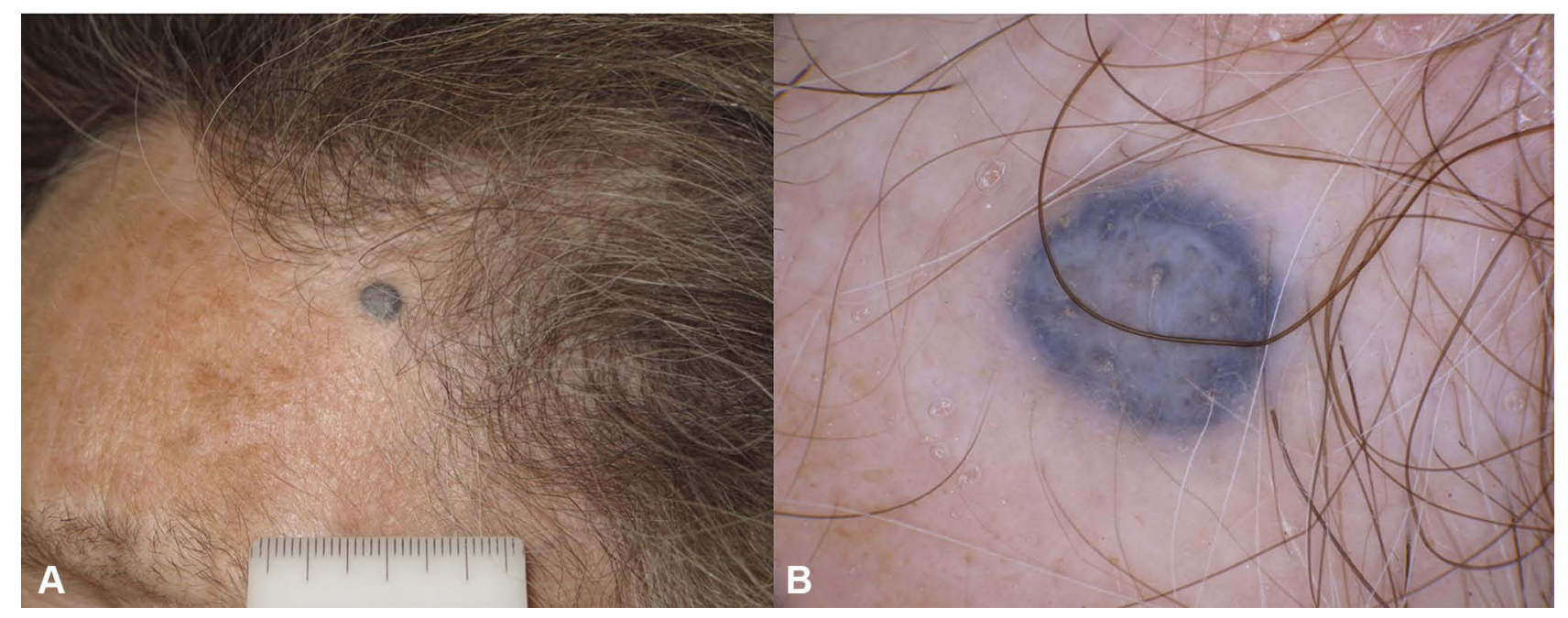

Figure 8 Blue nevus. (A) A blue papule on the frontal area of a 50-year old woman. (B) In dermoscopy structureless blue pigmentation is detected.

gives instructions for the excision margins. Surgery should be performed with resection margins, as for other cutaneous melanomas. ${ }^{47}$ The in situ lesions are excised with a safety margin of 5-mm of surrounding normal skin. Thin $(<1 \mathrm{~mm})$ melanomas need excision with $1-\mathrm{cm}$ margins. For intermediate thickness (1-4 mm) melanomas, the safety margins of excision are $2-\mathrm{cm}$. For melanomas $>4 \mathrm{~mm}$ of Breslow thickness excision margins of $3 \mathrm{~cm}$ are suggested ${ }^{48}$ Most excisional defects of the scalp melanomas are reconstructed with split thickness skin grafts.
Rarely flap coverage is required, especially in defects where the bony skull has also been removed ${ }^{49}$ (many studies compared narrow $(1$ or $2 \mathrm{~cm})$ to wide $(3-5 \mathrm{~cm}))$ margins, and none of these identified a difference in local recurrence or overall survival between the narrow or wide margin groups. ${ }^{43-46}$ One study, however, found a significant increase in regional recurrence for narrow margins for patients with melanoma thicker than $2 \mathrm{~mm}$, while for thin melanoma, excision margins of less than $1 \mathrm{~cm}$ increased the risk of local recurrence. ${ }^{50}$ 


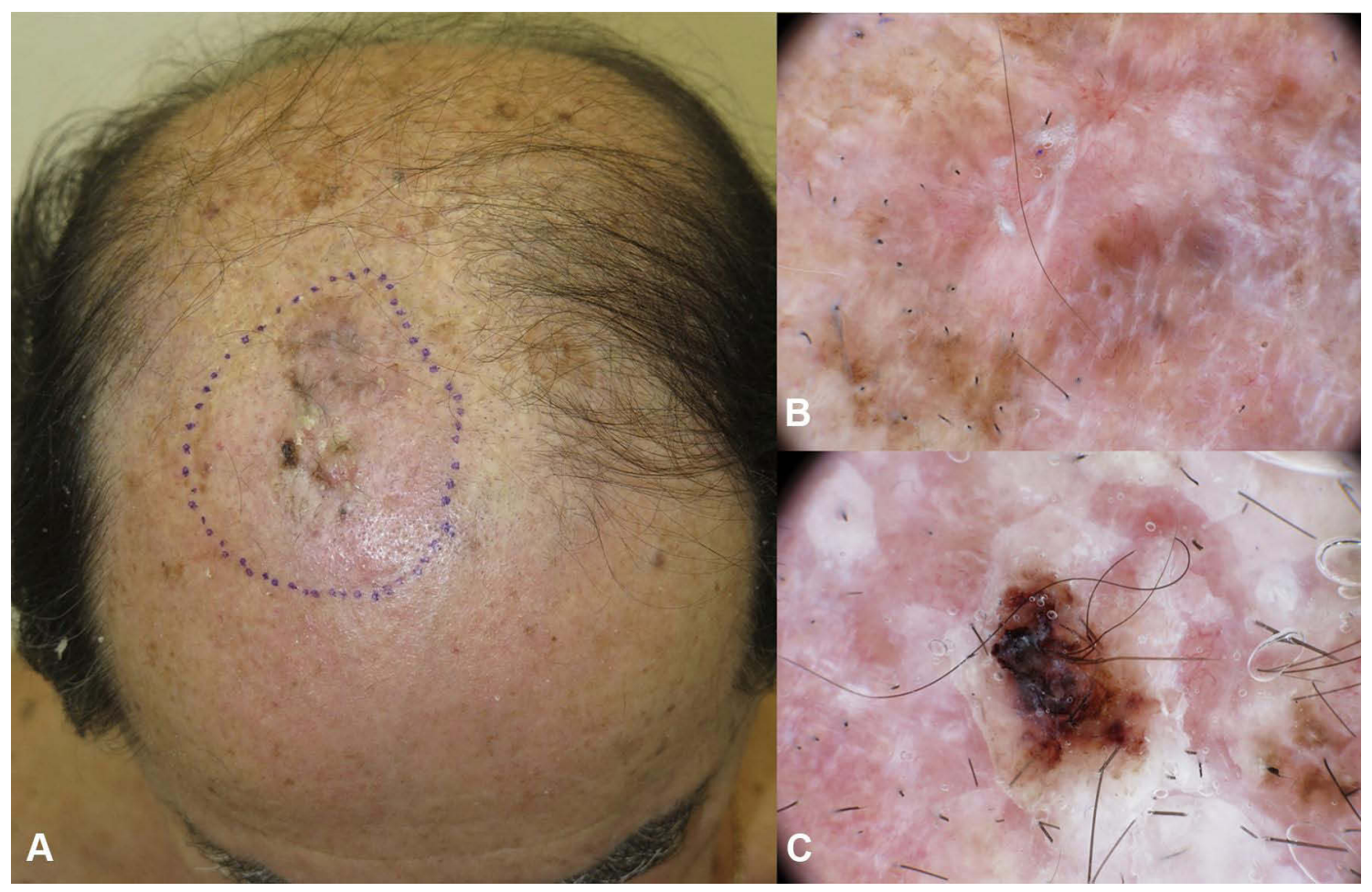

Figure 9 Invasive melanoma on the parietal region in a 75-year-old man with androgenic alopecia, superficial spreading melanoma 3.3 mm Breslow thickness (A) The lesion appears partially nodular with not-defined borders. (B, C) In dermoscopy a unspecific pattern is detected with brownish pigmentation, white lines and milky red areas.

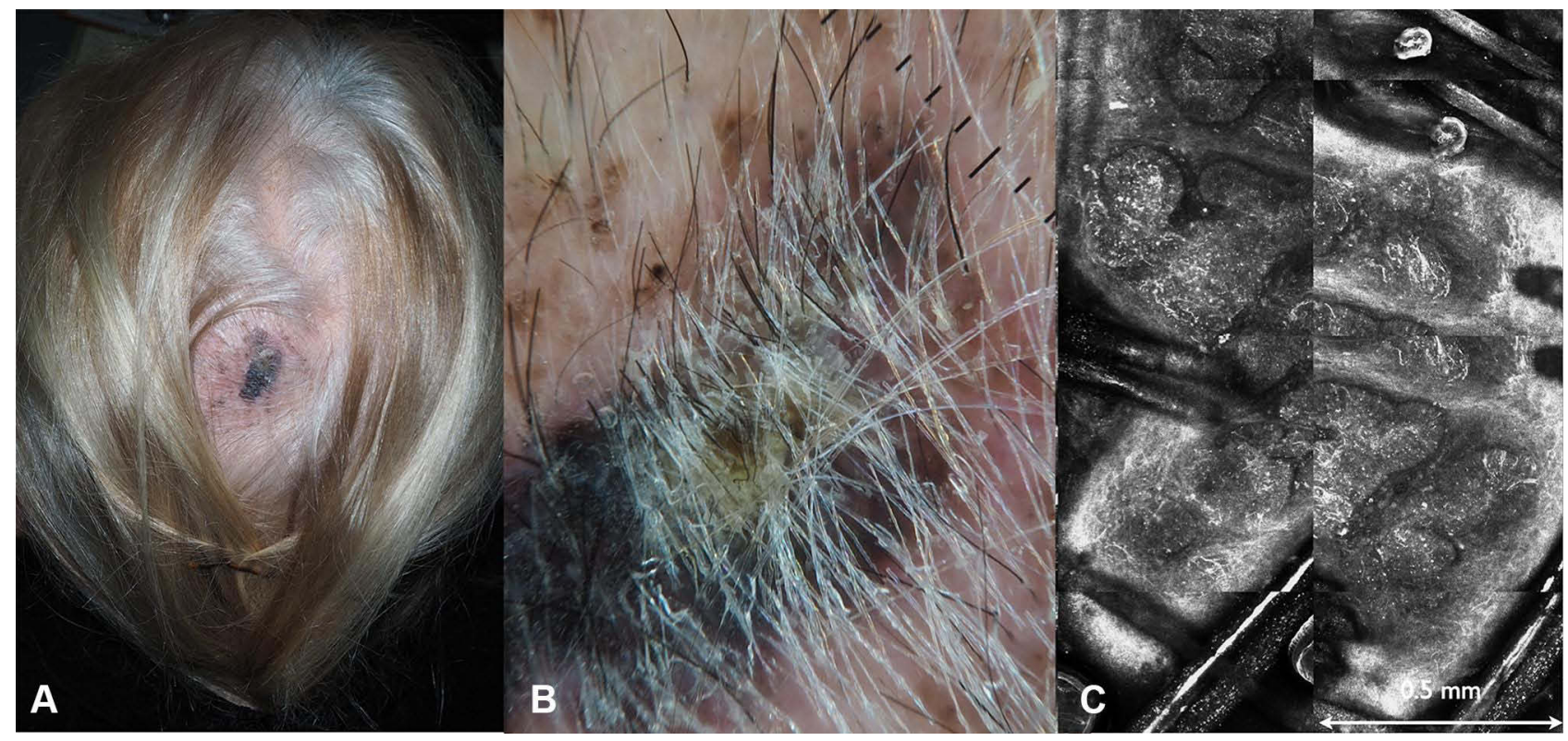

Figure 10 Pigmented basal cell carcinoma on the vertex in a 72-year old woman. (A) Clinically a heavily pigmented lesion with ill defined borders and superficial crusts. (B) Dermoscopy, highlighting the presence of black pigmentation and grey blue ovoid nests. (C) RCM. Confocal mosaic $(2 \times 1 \mathrm{~mm})$ at the level of the dermal epidermal junction showing multiple basaloid islands, visible as basaloid nests with palisading and clefting and the surrounding vascular structures.

On the matter of sentinel lymph node biopsy (SLNB) of SM, obstacles might be encountered, as in this region the lymphatic drainage system is complex, and therefore more unpredictable head and neck lymphatic system consist in more of 300 lymph nodes packed with a usual discordance between clinical lymphatic drainage pathways and those identified by lymphoscintigraphy. ${ }^{51}$ Moreover, the possibility of localization of the sentinel 


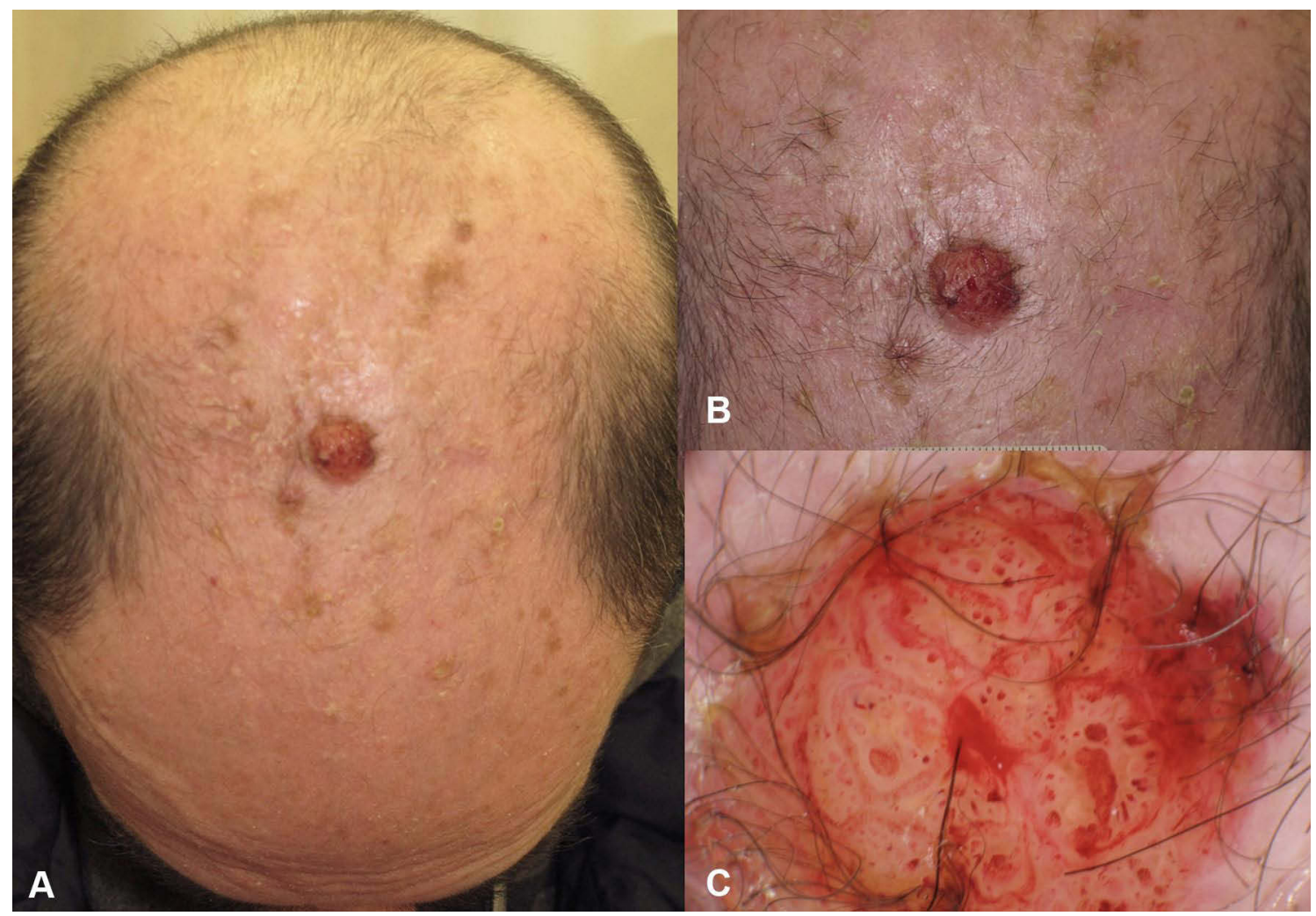

Figure I I (A) Amelanotic nodular melanoma on the scalp of a 75-year old man, $4.5 \mathrm{~mm}$ Breslow thickness. (B) Close up of the non pigmented nodule. (C) In dermoscopy atypical vascular pattern is detected.

lymph node in the parotid gland, with the risk of damage of the facial nerve, makes SNLB for scalp melanoma a debated choice. As SM are known to be biologically more aggressive and are often thicker at the presentation, SLNB is strongly advocated even in thinner lesions by many authors. ${ }^{52,53}$ Carmichael et $\mathrm{al}^{54}$ reported that the scalp sentinel lymph nodes in posterior auricular or occipital region were frequent drainage sites for SM and when detected by SLNB, had a $30 \%$ rate of having a metastatic disease.

A study by Cappello et al ${ }^{55}$ evaluated 405 patients with head and neck melanoma and compared clinicopathologic and prognostic factors associated with SM and non-scalp melanomas of the head and neck. In that study, SLN status was the strongest predictor of overall survival in patients with melanoma of the scalp while tumour thickness and ulceration correlated with overall survival in patients with non-scalp melanomas of the head and neck. There is a clear consensus on performing SNLB for cutaneous melanoma having a Breslow thickness of 1-4 mm; however, the reasoning of SNLB in thin melanomas is debated.

Patients should be staged according to the American Joint Committee on Cancer (AJCC) guidelines and be treated accordingly. In advanced stages, patients may undergo immunotherapy or targeted therapy, depending on the presence or absence of BRAF mutation and on associated co-morbidities. ${ }^{56}$

The most frequent agents for immunotherapy are AntiPD1 and anti-cytotoxic T-lymphocyte antigen (CTLA)-4 monoclonal antibody combinations, such as nivolumab and ipilimumab, that have been used in the last few years. More recently, pembrolizumab has been shown to achieve high response rates and therefore has also become an option for advanced diseases. For the melanomas that have BRAF mutations identified, targeted treatment for the RAS-RAF-ERK and P13K pathways are more effective, and usually BRAF/MEK inhibitor therapy, such as vemurafenib, cobimetinib and dabrafenib are employed.

Unfortunately, scalp melanomas commonly have predominant CCND1 and CDK4 oncogenes and therefore are less likely to respond to target therapy. ${ }^{57}$

The application of topical imiquimod has been described for the treatment of cutaneous metastases and lentigo maligna but mostly in reports, small case series or retrospective case series. As well known, imiquimod is a nucleoside analogue of the imidazoquinoline family and 


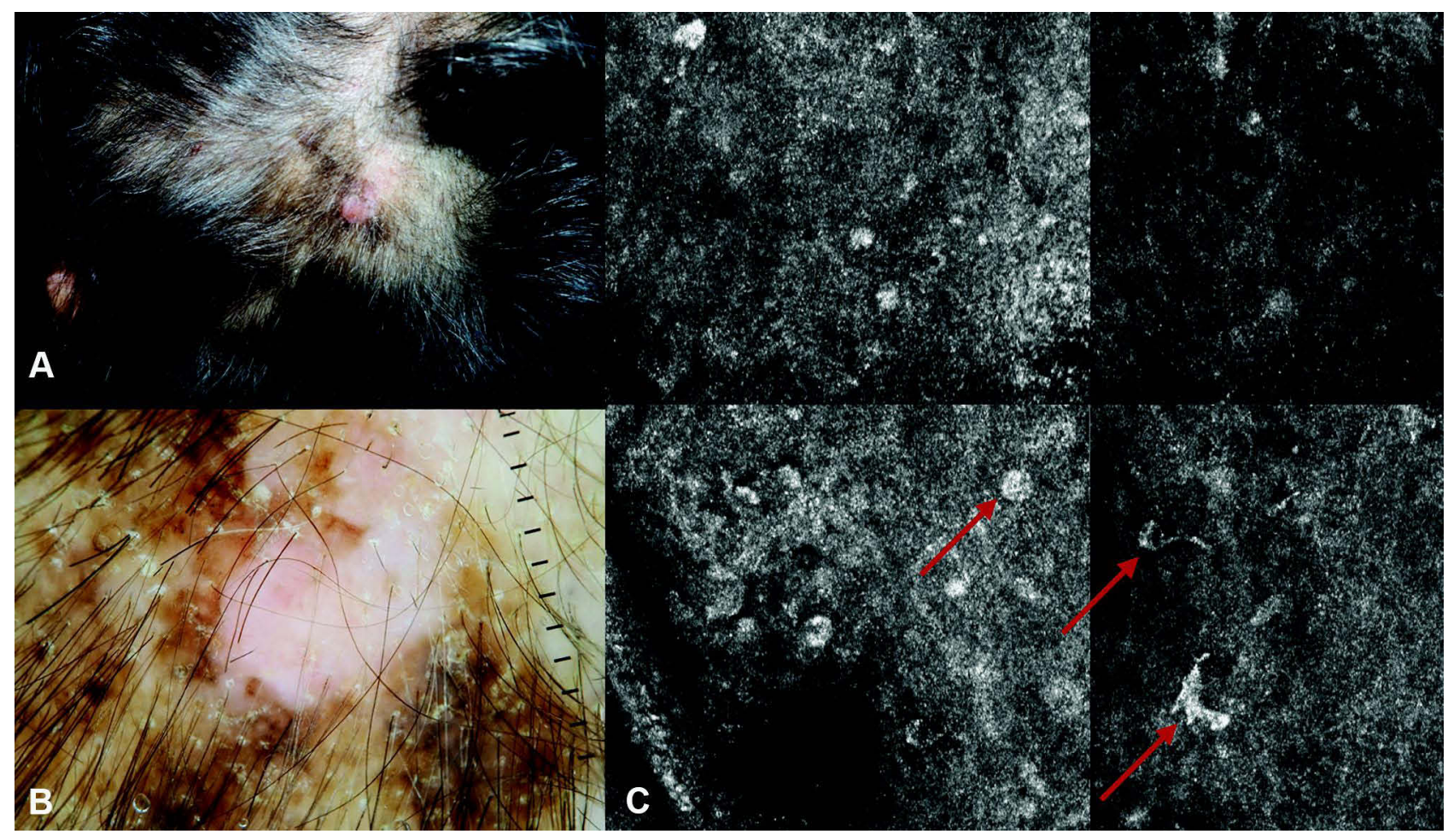

Figure 12 Desmoplastic melanoma on the scalp of a 68-year old woman. (A) Clinical appearance of the dome-shaped melanotic papule, with surrounding brownish macule. (B) The dome shaped papule corresponds to the invasive desmoplastic component, the brown-greyish macule with pseudo network corresponds to the lentigo maligna component. (C) RCM image highlighting the presence of atypical melanocytes (red arrows).

it was originally designed as an antiviral agent. As it exerts its main role as an agonist activity of Toll-like receptors, it may also have a role as adjuvant therapy after regular surgical treatment, as it enhances the functional maturation of Langerhans cells promoting their migration to lymph nodes and the beginning of a cell-T specific immune response. ${ }^{58,59}$ The behavior of SM is different from melanomas arising at other body sites and the overall survival compared with other head and neck melanomas is lower ${ }^{60}$ Taking into account local recurrence SM have higher recurrence rates compared to other sites of the head and neck. Recurrence rate for scalp melanoma is $13 \%$ compared to $5 \%$ for melanoma of the face neck and ear according to Shaw et al. ${ }^{61}$ Therefore, it is important to make a diagnosis as early as possible.

\section{Conclusions}

SM tends to behave more aggressively, have higher rates of recurrence and higher mortality as compared to melanoma on other body sites. Increasing awareness on this "invisible killer" is crucial. Their aggressive course request for more careful surveillance as a component of general skin screening for melanoma. It is advisable for doctors and patients to include scalp examination in their routine skin check. Dermoscopy and RCM can be helpful in identifying early lesions, making a correct diagnosis, and lead to improved patents' management.

\section{Funding}

There is no funding to report.

\section{Disclosure}

The authors report no conflicts of interest in this work.

\section{References}

1. Wood RP, Heyworth JS, McCarthy NS, et al. Association of known melanoma risk factors with primary melanoma of the scalp and neck. Cancer Epidemiol Biomarkers Prev. 2020;29(11):2203-2210. doi:10.1158/1055-9965.EPI-20-0595

2. Dabouz F, Barbe C, Lesage C, et al. Clinical and histological features of head and neck melanoma: a population-based study in France. $\mathrm{Br}$ J Dermatol. 2015;172(3):707-715. doi:10.1111/bjd.13489

3. Lachiewicz AM, Berwick M, Wiggins CL, Thomas NE. Survival differences between patients with scalp or neck melanoma and those with melanoma of other sites in the Surveillance, Epidemiology, and End Results (SEER) program. Arch Dermatol. 2008;144(4):515-521. doi:10.1001/archderm.144.4.515

4. de Giorgi V, Rossari S, Gori A, et al. The prognostic impact of the anatomical sites in the 'head and neck melanoma': scalp versus face and neck. Melanoma Res. 2012;22(5):402-405. doi:10.1097/ CMR.0b013e3283577b96 
5. Sparks DS, Read T, Lonne M, et al. Primary cutaneous melanoma of the scalp: patterns of recurrence. J Surg Oncol. 2017;115(4):449-454. doi: $10.1002 /$ jso. 24535

6. Ozao-Choy J, Nelson DW, Hiles J, et al. The prognostic importance of scalp location in primary head and neck melanoma. J Surg Oncol. 2017;116(3):337-343. doi:10.1002/jso.24679

7. Terakedis BE, Anker CJ, Leachman SA, et al. Patterns of failure and predictors of outcome in cutaneous malignant melanoma of the scalp. $J$ Am Acad Dermatol. 2014;70(3):435-442. doi:10.1016/j. jaad.2013.10.028

8. Porto AC, Pinto Blumetti T, Oliveira Santos Filho IDA, et al. Primary cutaneous melanoma of the scalp: patterns of clinical, histological and epidemiological characteristics in Brazil. PLoS One. 2020;15 (10):e0240864. doi:10.1371/journal.pone.0240864

9. Fadaki N, Li R, Parrett B, et al. Is head and neck melanoma different from trunk and extremity melanomas with respect to sentinel lymph node status and clinical outcome? Ann Surg Oncol. 2013;20 (9):3089-3097. doi:10.1245/s10434-013-2977-7

10. Gillgren P, Månsson-Brahme E, Frisell J, Johansson H, Larsson O, Ringborg U. A prospective population-based study of cutaneous malignant melanoma of the head and neck. Laryngoscope. 2000;110 (9):1498-1504. doi:10.1097/00005537-200009000-00017

11. Lesage C, Barbe C, Le Clainche A, Lesage FX, Bernard P, Grange F. Sex-related location of head and neck melanoma strongly argues for a major role of sun exposure in cars and photoprotection by hair. J Invest Dermatol. 2013;133(5):1205-1211. doi:10.1038/jid.2012.405

12. Benati E, Longo C, Bombonato C, Moscarella E, Alfano R, Argenziano G. Baldness and scalp melanoma. J Eur Acad Dermatol Venereol. 2017;31(12):e528-e530. doi:10.1111/jdv.14395

13. Green AC, Kimlin M, Siskind V, Whiteman DC. Hypothesis: hair cover can protect against invasive melanoma on the head and neck (Australia). Cancer Causes Control. 2006;17(10):1263-1266. doi:10.1007/s10552-006-0063-1. PMID: 17111257; PMCID: PMC1705485.

14. Pereira AR, Collgros H, Guitera P, et al. Melanomas of the scalp: is hair coverage preventing early diagnosis? Int J Dermatol. 2021;60 (3):340-346. doi:10.1111/ijd.15283

15. Black NR, O'Reilly GA, Pun S, Black DS, Woodley DT. Improving hairdressers' knowledge and self-efficacy to detect scalp and neck melanoma by use of an educational video. JAMA Dermatol. 2018;154 (2):214-216. doi:10.1001/jamadermatol.2017.4267. PMID: 29214298.

16. Robinson JK. Skin check partner assistance for melanoma skin self-examination by at-risk patients: it takes two to identify melanomas. Future Oncol. 2020;16(16):1065-1068. doi:10.2217/ fon-2020-0265. PMID: 32292057; PMCID: PMC7273363.

17. Devitt B, Liu W, Salemi R, et al. Clinical outcome and pathological features associated with NRAS mutation in cutaneous melanoma. Pigment Cell Melanoma Res. 2011;24(4):666-672. doi:10.1111/ j.1755-148X.2011.00873.x

18. Saaiq M, Zalaudek I, Rao B, et al. A brief synopsis on scalp melanoma. Dermatol Ther. 2020;33(4):e13795. doi:10.1111/ dth. 13795

19. Lee JH, Choi JW, Kim YS. Frequencies of BRAF and NRAS mutations are different in histological types and sites of origin of cutaneous melanoma: a meta-analysis. Br J Dermatol. 2011;164 (4):776-784. doi:10.1111/j.1365-2133.2010.10185.x

20. Jiveskog S, Ragnarsson-Olding B, Platz A, Ringborg U. N-ras mutations are common in melanomas from sun-exposed skin of humans but rare in mucosal membranes or unexposed skin. J Invest Dermatol. 1998;111(5):757-761. doi:10.1046/j.1523-1747.1998.00376.x

21. Howard MD, Wee E, Wolfe R, McLean CA, Kelly JW, Pan Y. Anatomic location of primary melanoma: survival differences and sun exposure. $J$ Am Acad Dermatol. 2019;81(2):500-509. doi:10.1016/j.jaad.2019.04.034
22. King R, Page RN, Googe PB, Mihm MC Jr. Lentiginous melanoma: a histologic pattern of melanoma to be distinguished from lentiginous nevus. Mod Pathol. 2005;18(10):1397-1401. doi:10.1038/modpathol.3800454. PMID: 15976811.

23. Chen LL, Jaimes N, Barker CA, Busam KJ, Marghoob AA. Desmoplastic melanoma: a review. J Am Acad Dermatol. 2013;68 (5):825-833. doi:10.1016/j.jaad.2012.10.041. PMID: 23267722; PMCID: PMC4703041.

24. Bastian BC. The molecular pathology of melanoma: an integrated taxonomy of melanocytic neoplasia. Annu Rev Pathol. 2014;9:239-271. doi:10.1146/annurev-pathol-012513-104658. PMID: 24460190; PMCID: PMC4831647.

25. Hodi FS, Corless CL, Giobbie-Hurder A, et al. Imatinib for melanomas harboring mutationally activated or amplified KIT arising on mucosal, acral, and chronically sun-damaged skin. J Clin Oncol. 2013;31(26):3182-3190. doi:10.1200/JCO.2012.47.7836. PMID: 23775962; PMCID: PMC4878082.

26. Mar VJ, Wong SQ, Li J, et al. BRAF/NRAS wild-type melanomas have a high mutation load correlating with histologic and molecular signatures of UV damage. Clin Cancer Res. 2013;19(17):4589-4598. doi:10.1158/1078-0432.CCR-13-0398. PMID: 23833303.

27. Elder DE, Bastian BC, Cree IA, Massi D, Scolyer RA. The 2018 World Health Organization classification of cutaneous, mucosal, and uveal melanoma: detailed analysis of 9 distinct subtypes defined by their evolutionary pathway. Arch Pathol Lab Med. 2020;144 (4):500-522. doi:10.5858/arpa.2019-0561-RA. PMID: 32057276.

28. Stanganelli I, Argenziano G, Sera F, et al. Dermoscopy of scalp tumours: a multi-centre study conducted by the international dermoscopy society. J Eur Acad Dermatol Venereol. 2012;26(8):953-963. doi:10.1111/j.1468-3083.2011.04188.x

29. Zalaudek I, Leinweber B, Soyer HP, Petrillo G, Brongo S, Argenziano G. Dermoscopic features of melanoma on the scalp. J Am Acad Dermatol. 2004;51(2 Suppl):S88-90. doi:10.1016/j. jaad.2003.12.024

30. Benati E, Longo C, Piana S, Moscarella E. Preliminary evaluation of reflectance confocal microscopy features of scalp melanoma. Australas J Dermatol. 2017;58(4):312-316. doi:10.1111/ajd.12690. PMID: 28752561.

31. Schiffner R, Schiffner-Rohe J, Vogt T, et al. Improvement of early recognition of lentigo maligna using dermatoscopy. $J$ Am Acad Dermatol. 2000;42(1 Pt 1):25-32. doi:10.1016/s0190-9622(00) 90005-7

32. Tschandl P, Gambardella A, Boespflug A, et al. Seven non-melanoma features to rule out facial melanoma. Acta Derm Venereol. 2017;97 (10):1219-1224. doi:10.2340/00015555-2759

33. Argenziano G, Fabbrocini G, Carli P, De Giorgi V, Sammarco E, Delfino M. Epiluminescence microscopy for the diagnosis of doubtful melanocytic skin lesions. Comparison of the $\mathrm{ABCD}$ rule of dermatoscopy and a new 7-point checklist based on pattern analysis. Arch Dermatol. 1998;134(12):1563-1570. doi:10.1001/ archderm.134.12.1563

34. Pampena R, Kyrgidis A, Lallas A, Moscarella E, Argenziano G, Longo C. A meta-analysis of nevus-associated melanoma: prevalence and practical implications. J Am Acad Dermatol. 2017;77(5):938945.e4. doi:10.1016/j.jaad.2017.06.149. PMID: 28864306.

35. Shitara D, Nascimento M, Ishioka P, et al. Dermoscopy of naevus-associated melanomas. Acta Derm Venereol. 2015;95 (6):671-675. doi:10.2340/00015555-2009. PMID: 25394499.

36. Greco V, Cappello M, Megna M, et al. Dermoscopic patterns of intradermal naevi. Austr $J$ Dermatol. 2020;61(4):337-341. doi:10.1111/ajd.13366. PMID: 32715462.

37. Argenziano G, Longo C, Cameron A, et al. Blue-black rule: a simple dermoscopic clue to recognize pigmented nodular melanoma. $\mathrm{Br}$ $J \quad$ Dermatol. 2011;165(6):1251-1255. doi:10.1111/j.13652133.2011.10621.x. PMID: 21916885. 
38. Cavicchini S, Tourlaki A, Bottini S. Dermoscopic vascular patterns in nodular "pure" amelanotic melanoma. Arch Dermatol. 2007;143 (4):556. doi:10.1001/archderm.143.4.556. PMID: 17438200.

39. Jaimes N, Chen L, Dusza SW, et al. Clinical and dermoscopic characteristics of desmoplastic melanomas. JAMA Dermatol. 2013;149(4):413-421. doi:10.1001/jamadermatol.2013.2248. PMID 23325288.

40. Garbarino F, Pampena R, Lai M, et al. Flat scalp melanoma dermoscopic and reflectance confocal microscopy features correspond to histopathologic type and lesion location. J Eur Acad Dermatol Venereol. 2021. doi:10.1111/jdv.17313. PMID: 28752561.

41. Shellenberger RA, Fayyaz F, Sako Z, et al. Impact of biopsy technique on clinically important outcomes for cutaneous melanoma: a systematic review and meta-analysis. Mayo Clin Proc Innov Qual Outcomes. 2020;4(4):373-383. doi:10.1016/j.mayocpiqo.2020.04.0 05. PMID: 33960517.

42. Merkel EA, Amin SM, Lee CY, et al. The utility of dermoscopy-guided histologic sectioning for the diagnosis of melanocytic lesions: a case-control study. J Am Acad Dermatol. 2016;74 (6):1107-1113. doi:10.1016/j.jaad.2016.01.002. PMID: 32793865; PMCID: PMC7411171.

43. Waddell A, Star P, Guitera P. Advances in the use of reflectance confocal microscopy in melanoma. Melanoma Manag. 2018;5(1): MMT04. doi:10.2217/mmt-2018-0001. PMID: 26826889.

44. Burroni M, Wollina U, Torricelli R, et al. Impact of digital dermoscopy analysis on the decision to follow up or to excise a pigmented skin lesion: a multicentre study. Skin Res Technol. 2011;17 (4):451-460. doi:10.1111/j.1600-0846.2011.00518.x. PMID: 30190930; PMCID: PMC6122529.

45. Maurichi A, Miceli R, Camerini T, et al. Prediction of survival in patients with thin melanoma: results from a multi-institution study. $J$ Clin Oncol. 2014;32(23):2479-2485. doi:10.1200/JCO.20 13.54.2340

46. Zenga J, Nussenbaum B, Cornelius LA, Linette GP, Desai SC. Management controversies in head and neck melanoma: a systematic review. JAMA Facial Plast Surg. 2017;19(1):53-62. doi:10.1001/jamafacial.2016.1038

47. Gillgren P, Drzewiecki KT, Niin M, et al. 2-cm versus 4-cm surgical excision margins for primary cutaneous melanoma thicker than $2 \mathrm{~mm}$ : a randomised, multicentre trial. Lancet. 2011;378 (9803):1635-1642. doi:10.1016/S0140-6736(11)61546-8

48. Narayan D, Ariyan S. Surgical management of the primary melanoma. Clin Plast Surg. 2000;27(3):409-19, viii-ix.

49. Bogle M, Kelly P, Shenaq J, Friedman J, Evans GR. The role of soft tissue reconstruction after melanoma resection in the head and neck. Head Neck. 2001;23(1):8-15. PMID: 10941561.
50. Ross MI, Balch CM. Excision margins of melanoma make a difference: new data support an old paradigm. Ann Surg Oncol. 2016;23(4):1053-1056. doi:10.1245/s10434-015-4950-0. PMID: 11190860 .

51. O'Brien CJ, Uren RF, Thompson JF, et al. Prediction of potential metastatic sites in cutaneous head and neck melanoma using lymphoscintigraphy. Am J Surg. 1995;170(5):461-466. doi:10.1016/ s0002-9610(99)80330-4

52. Giudice G, Leuzzi S, Robusto F, et al. Sentinel lymph node biopsy in head and neck melanoma*. G Chir. 2014;35(5-6):149-155. PMID: 7485733.

53. Puza CJ, Josyula S, Terando AM, et al. Does the number of sentinel lymph nodes removed affect the false negative rate for head and neck melanoma? J Surg Oncol. 2018;117(7):1584-1588. doi:10.1002/ jso.25025. PMID: 24979109; PMCID: PMC4321520.

54. Carmichael H, King BBT, Friedman C, et al. Frequency and implications of occipital and posterior auricular sentinel lymph nodes in scalp melanoma. J Surg Oncol. 2019;120(8):1470-1475. doi:10.1002/jso.25715. PMID: 29513892.

55. Cappello ZJ, Augenstein AC, Potts KL, McMasters KM, Bumpous JM. Sentinel lymph node status is the most important prognostic factor in patients with melanoma of the scalp. Laryngoscope. 2013;123(6):1411-1415. doi:10.1002/lary.23793

56. Zahnreich S, Mayer A, Loquai C, Grabbe S, Schmidberger H. Radiotherapy with BRAF inhibitor therapy for melanoma: progress and possibilities. Future Oncol. 2016;12(1):95-106. doi:10.2217/ fon. 15.297

57. Wilden SM, Lang BM, Mohr P, Grabbe S. Immune checkpoint inhibitors: a milestone in the treatment of melanoma. J Dtsch Dermatol Ges. 2016;14(7):685-695. doi:10.1111/ddg.13012

58. Scarfî F, Patrizi A, Veronesi G, et al. The role of topical imiquimod in melanoma cutaneous metastases: a critical review of the literature. Dermatol Ther. 2020;33(6):e14165. doi:10.1111/dth.14165

59. Lallas A, Moscarella E, Kittler H, et al. Real-world experience on off-label use of imiquimod $5 \%$ as an adjuvant therapy after surgery or as a monotherapy for lentigo maligna. Br J Dermatol. 2021. doi:10.1111/bjd.20407

60. Ng AK, Jones WO, Shaw JH. Analysis of local recurrence and optimizing excision margins for cutaneous melanoma. Br J Surg. 2001;88(1):137-142. doi:10.1046/j.1365-2168.2001.01611.x. PMID: 11136327.

61. Shaw HM, McCarthy WH, McCarthy SW, Milton GW. Thin malignant melanomas and recurrence potential. Arch Surg. 1987;122 (10):1147-1150. doi:10.1001/archsurg.1987.01400220057011. PMID: 3662794 .
Clinical, Cosmetic and Investigational Dermatology

\section{Publish your work in this journal}

Clinical, Cosmetic and Investigational Dermatology is an international, peer-reviewed, open access, online journal that focuses on the latest clinical and experimental research in all aspects of skin disease and cosmetic interventions. This journal is indexed on CAS.
The manuscript management system is completely online and includes a very quick and fair peer-review system, which is all easy to use. Visit http://www.dovepress.com/testimonials.php to read real quotes from published authors. 